\title{
Impact of COVID-19 on air quality in the Yangtze River Delta, China
}

\author{
Lan Yao $\mathbb{D} \cdot$ Weiyue Li $\cdot$ Yi Du
}

Received: 18 September 2020 / Accepted: 22 July 2021 / Published online: 27 July 2021

(C) The Author(s), under exclusive licence to Springer Nature Switzerland AG 2021

\begin{abstract}
To investigate the effect of nationwide restrictions due to COVID-19 on air quality in the Yangtze River Delta (YRD), China, we defined four periods named period I (January 1 to 23, 2020), period II (January 24 to February 23), period III (February 24 to April 7), and period IV (April 8 to May 31), which indicated normal period, lockdown period, regional work resumption period, and nationwide work resumption period, respectively. Hourly $\mathrm{PM}_{2.5}, \mathrm{PM}_{10}, \mathrm{NO}_{2}, \mathrm{SO}_{2}, \mathrm{CO}$, and $\mathrm{O}_{3}$ in 41 cities in the YRD region were analyzed. Compared to period I, $\mathrm{NO}_{2}$ decreased by $58 \%$ during period II and increased in periods III and IV. $\mathrm{SO}_{2}$ remained constant during the four periods $\left(7-8 \mu \mathrm{g} / \mathrm{m}^{3}\right)$. Higher $\mathrm{PM}_{2.5}$ concentration was monitored during period II $\left(41 \mu \mathrm{g} / \mathrm{m}^{3}\right)$ when compared to period III $\left(35 \mu \mathrm{g} / \mathrm{m}^{3}\right)$, which was resulted from the enhanced secondary formation. Spatial distribution analysis further indicated that $\mathrm{PM}_{2.5}$ in the northern YRD during period II was higher than that during period III, whereas $\mathrm{PM}_{2.5}$ in the southern YRD in the period II was similar to that in period III. The results demonstrated that $\mathrm{PM}_{2.5}$ shows a nonlinear response to the reduction of its precursors, and
\end{abstract}

Supplementary Information The online version contains supplementary material available at https://doi. org/10.1007/s10661-021-09342-1.

L. Yao $(\bowtie) \cdot$ W. Li $\cdot$ Y. Du

School of Environmental and Geographical Sciences, Shanghai Normal University, Shanghai 200234, China e-mail: yaolan@shnu.edu.cn this phenomenon varies in different areas. Compared to periods I $\left(36 \mu \mathrm{g} / \mathrm{m}^{3}\right)$ and III $\left(64 \mu \mathrm{g} / \mathrm{m}^{3}\right)$, relatively higher $\mathrm{O}_{3}$ during period II $\left(64 \mu \mathrm{g} / \mathrm{m}^{3}\right)$ was probably resulted from less NO emission and hence weakened NO titration effect. The study suggested that coordinated and balanced measures are needed to improve air quality.

Keywords Coronavirus $\cdot \mathrm{NO}_{2} \cdot \mathrm{PM}_{2.5}$. Spatiotemporal variation · Yangtze River Delta

\section{Introduction}

The ongoing outbreak of COVID-19 has attacked 216 countries and areas, causing more than 16 million confirmed cases and 655,112 deaths globally as of 29 July 2020 (WHO, 2020). The outbreak of COVID-19 in China occurred after the Chinese Spring Festival (Festival) which was featured by high-intensity population mobility. Before the festival, numerous migrant residents come back to their hometowns to celebrate family reunions and return to the city for school and work after the holiday (Yao et al., 2019). For example, the migrant population across provinces in the Yangtze River Delta (YRD) region accounted for 71.7\% in 2017 (National Health Commission of the People's Republic of China, 2019). COVID-19 is transmitted through human respiratory droplets, direct contact, and even aerosol transmission (Liu et al., 
2020). To control the movement of its population to avoid infection after the 2020 Festival, China implemented nationwide restrictions. For example, the traditional 7-day festival was extended to 18 days (from January 24 to February 10). Besides, 14 days of quarantine was required after people return to their working and living cities and schools closed. Thus, COVID-19 caused large-scale and prolonged shutdowns in urban areas, leading to a large reduction of the primary emission.

The effectiveness of anthropogenic emission reduction on air quality has been a concerning issue for researchers. Previous studies investigated the role of short-term pollutant emission control measures in air quality improvement during the 2008 Beijing Olympics (8-24 August, Wang et al., 2010; Witte et al., 2009), the 2010 Guangzhou Asian Games (12-27 November, Liu et al., 2013; Tao et al., 2015; Yao et al., 2013), the 2014 Asia-Pacific Economic Cooperation (APEC) meeting (5-11 November, Guo et al., 2016; Tang et al., 2015; Xu et al., 2019), and the 7-day festival (Huang et al., 2012; Jiang et al., 2015; Yao et al., 2019). The COVID-19 provided a unique chance to test the sensitivity of primary emission reduction on air quality (Huang et al., 2020; Zhang et al., 2020; Zheng et al., 2020). Zheng et al. investigated the variations in chemical compositions, source contributions, and regional transport of $\mathrm{PM}_{2.5}$ from January 23 to February 22, 2020, compared with the same period in 2019 (Zheng et al., 2020). Zhang et al. reported $\mathrm{NO}_{x}$ emission reduction and recovery during COVID-19 in East China from January 1 to March 12, 2020 (Zhang et al., 2020). Huang et al. investigated the haze formation mechanism in the case of a reduction of primary emissions in East China from January to February 2020 (Huang et al., 2020). As the COVID-19 infection continues, studies of its impact on air quality on longer time scales are desirable.

The YRD region is severely affected by the epidemic. For example, the Shanghai government listed Hubei Province and another 19 cities as severely affected areas in China, among which 9 cities are located in the YRD region (https://www.shaimeiba.com/baike/shenghuo/18068. html). This study investigated the effects of COVID-19 on air quality based on 5 months of hourly concentration of $\mathrm{PM}_{2.5}, \mathrm{PM}_{10}, \mathrm{NO}_{2}, \mathrm{SO}_{2}, \mathrm{CO}$, and $\mathrm{O}_{3}$ in 41 cities in the YRD region. Spatial-temporal variation and daily pattern of air pollutants and comparison of changes in 2019 were discussed.

\section{Methods}

Monitoring datasets

Hourly concentrations of $\mathrm{PM}_{2.5}, \mathrm{PM}_{10}, \mathrm{NO}_{2}, \mathrm{SO}_{2}$, $\mathrm{CO}$, and $\mathrm{O}_{3}$ in 41 cities of the YRD from January 1, 2020 to May 31, 2020 were obtained from the National Urban Air Quality Real-Time Publishing Platform (http://106.37.208.233:20035/) of China National Environmental Monitoring Centre. Each city was equipped with several air quality automatic monitoring stations (urban assessing stations). Some cities with special geographical location were additionally equipped with one regional assessing stations (marked as Duizhaodian on the Platform). Hourly concentrations of pollutants in each city were averaged from all the monitoring stations except the regional assessing stations (Duizhaodian). Hourly mean concentrations of pollutants of YRD region were averaged from those of the 41 cities. The 41 cities include 13 cities in Jiangsu Province, 11 cities in Zhejiang Province, 16 cities in Anhui Province, and Shanghai.

\section{Important time nodes}

To investigate the effects of reduced anthropogenic activities as COVID-19 on air quality, we divided the whole study period as four specific periods based on three important time nodes. On January 23 , Wuhan, the first place of the outbreak of coronavirus, declared unprecedented traffic restrictions, including suspending the city's public transport and all outbound flights and trains. This event marked the beginning of lockdown in China. Shanghai, the leading city of the YRD region, announced that work resumption should not be earlier than February 9. It needs to be emphasized that most people have left the city before January 23 to return to their hometown for the Chinese Spring Festival (started from January 24), called as "Chunyun." Home quarantine is required for 14 days after they return to Shanghai before work resumption. Thus, the lockdown period lasted from January 24 to February 23. From February 24, massive resumption of work and production in urban areas were started in the YRD region. On 00:00, April 8, Wuhan started lifting outbound travel restrictions, which indicated ending lockdown all over China. Thus, the four periods 
were from January 1 to 23 , January 24 to February 23, February 24 to April 7, and April 8 to May 31, which were sequentially numbered as I, II, III, and IV, respectively, as seen in Fig. 1.

In period I, a few daily cases were reported and scarce containment measure was taken, which was considered as a normal period. On the contrary, the COVID-19 outbreak occurred during period II, and the most rigorous control measurements were implemented to reduce population mobility. In period III, almost no locally transmitted infections were recorded and the reported cases were sourced from virus carriers traveling from abroad. People started to resume work and normal life in YRD during this period. The domestic coronavirus is effectively under control in China during period IV, and this period represents a nationwide resumption of work and production. In summary, period I, period II, period III, and period IV represent prelockdown period, lockdown period, period of ending lockdown on urban scale, and period of ending lockdown on a national scale, respectively.

Processing of meteorological data

The original meteorological data is from the ERA5 reanalysis datasets (ERA5 hourly data on single levels from 1979 to present), which is provided by the
European Centre for Medium-Range Weather Forecasts (ECMWF). Variables including precipitation, total column water vapor, 10-m u-component of wind, and $10-\mathrm{m} \mathrm{v}$-component of wind were used in the present work, with horizontal resolution of $0.25^{\circ} \times 0.25^{\circ}$. The ERA5 atmospheric reanalysis was reported to have improved performance (Graham et al., 2019).

\section{Results}

Overview of air quality

The average concentrations of air pollutants in YRD during the four periods are depicted in Fig. 2. $\mathrm{NO}_{2}$, a primary pollutant from vehicle emission, presented the highest concentration during period I and significantly decreased during period II and then increased during periods III and IV, with concentrations of $39,16,29$, and $26 \mu \mathrm{g} / \mathrm{m}^{3}$ during the four sequential periods, respectively. Independent-sample $T$ test was applied to exam the significant difference in the mean value of $\mathrm{NO}_{2}$ during the four periods. Results show that there are significant differences in the average $\mathrm{NO}_{2}$ concentrations during period I, period II, and period III (both $P<0.01$ ), and no significant difference in periods III and IV $(P>0.05)$. Compared to periods $\mathrm{I}$ and III, $\mathrm{NO}_{2}$ decreased by $58 \%$ during

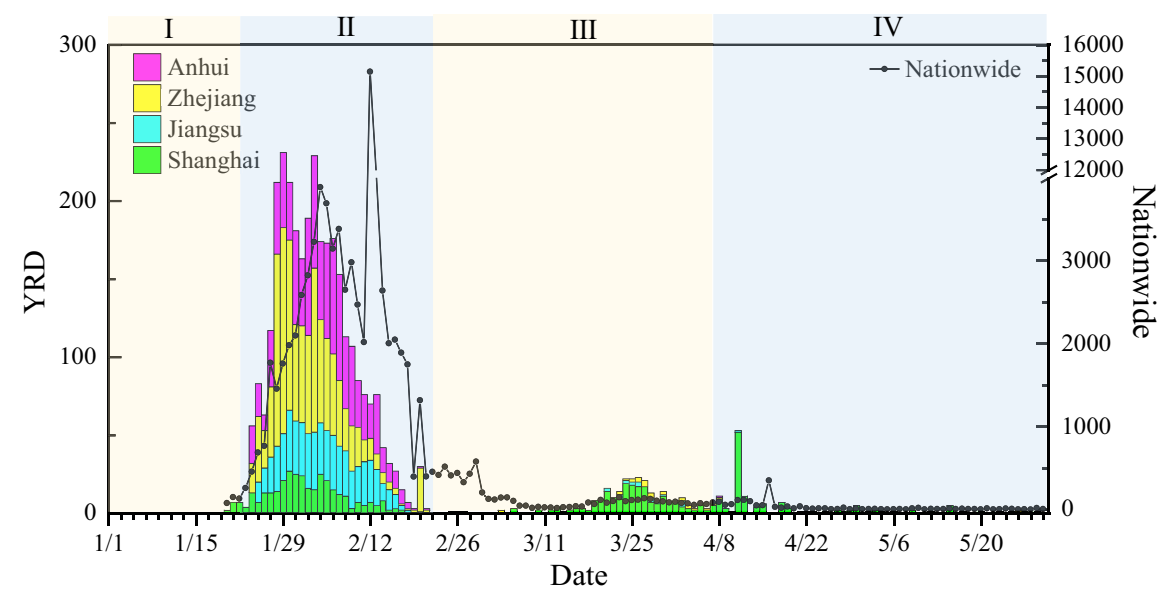

Fig. 1 Daily increases in new confirmed cases of COVID19 in the Yangzi River Delta (YRD) region, China. I, II, III, and IV indicate period I (from January 1 to 23 ), period II (from January 24 to February 23, period III (February 24 to April 7), and period IV (April 8 to May 31). Source: (Jiangsu
Commission of Health, 2020; Health Commission of Zhejiang Province, 2020; National Health Commission of the People's Republic of China, 2020; Shanghai Municipal Health Commission, 2020) 
Fig. 2 Statistics of the concentrations of $\mathrm{NO}_{2}, \mathrm{PM}_{2.5}$, $\mathrm{PM}_{10}, \mathrm{SO}_{2}, \mathrm{CO}$, and $\mathrm{O}_{3}$ during the four periods
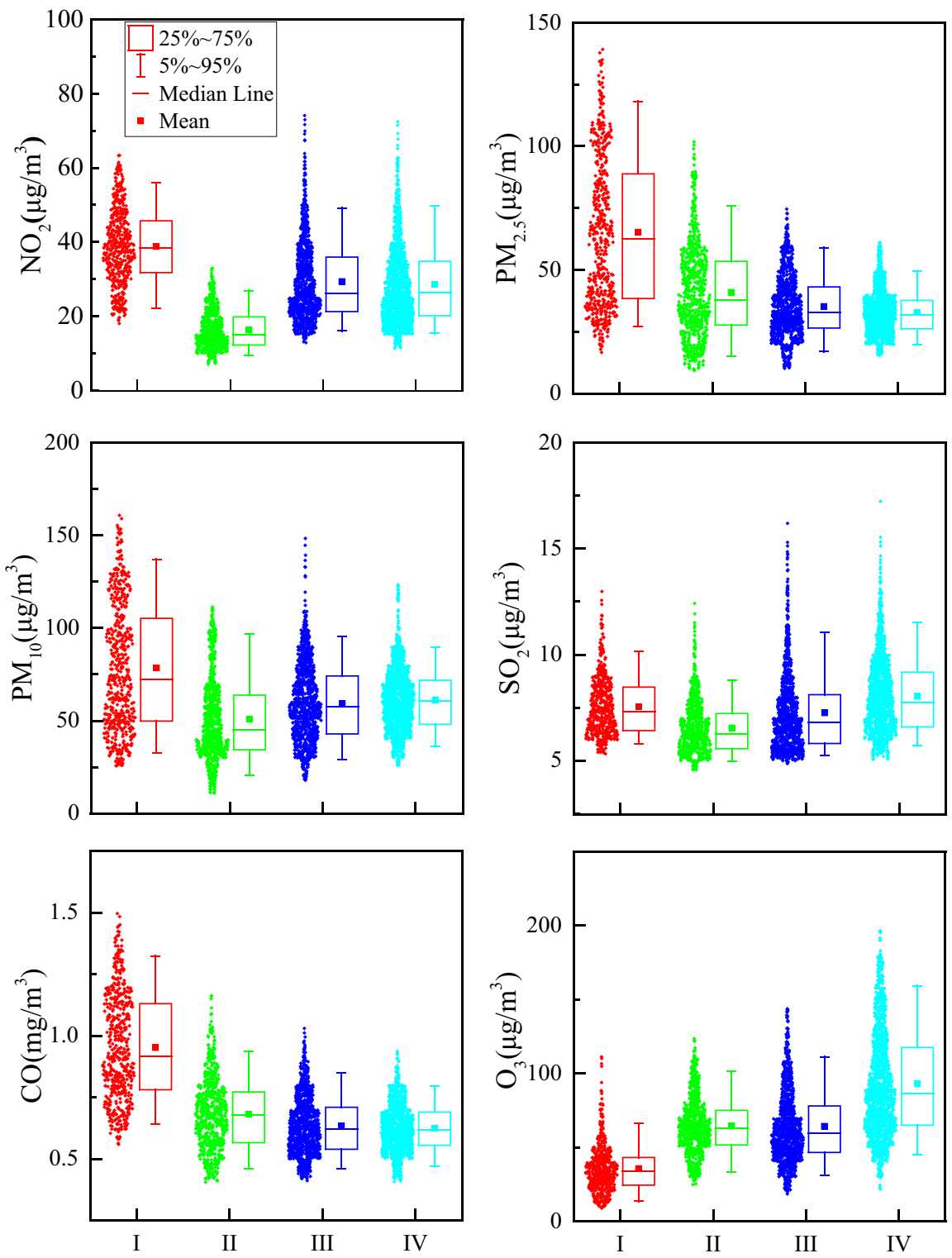

period II and increased by $81 \%$ during period III. However, $\mathrm{PM}_{2.5}$, mainly formed from secondary formation, did not exhibit such a variation trend. Concentrations of $\mathrm{PM}_{2.5}$ during the four periods were 65 , 41,35 , and $33 \mu \mathrm{g} / \mathrm{m}^{3}$, respectively. $T$ test indicated that $\mathrm{PM}_{2.5}$ concentration in period II was significantly $(P<0.01)$ higher than that in periods III and IV. Despite lower primary emission of pollutants in period II, higher $\mathrm{PM}_{2.5}$ indicated enhanced secondary formation (e.g. sulfate and nitrate) during period II, which was agreed well with the previous study (Chang et al., 2020; Huang et al., 2020). Huang et al.
(2020) measured major compositions of $\mathrm{PM}_{2.5}$ (e.g., sulfate, nitrate, ammonium, and organic matter) during the COVID-2019 lockdown and provided evidence that the heavy haze pollution in East China during the lockdown was triggered by enhancements of secondary pollution. Chang et al. (2020) observed fast formation of secondary inorganic (mostly nitrate) aerosols in Shanghai during the 2020 Chinese Spring Festival (lockdown period) and highlighted that regional transport facilitated nitrate formation.

Unlike $\mathrm{NO}_{2}, \mathrm{SO}_{2}$, a primary pollutant mainly from industrial emission, exhibited no significant variation, 
with concentrations of $8,7,7$, and $8 \mu \mathrm{g} / \mathrm{m}^{3}$ during the four periods. The latest study focusing on severe haze events characterized by high $\mathrm{PM}_{2.5}$ concentration in China during COVID-19 outbreak proposed that large emission reduction in transportation and a slight reduction in industrial would not help avoid severe air pollution in China (Wang et al., 2020).

$\mathrm{PM}_{10}$ displayed a similar variation pattern to $\mathrm{NO}_{2}$, with concentrations of $79,51,59$, and $61 \mu \mathrm{g} / \mathrm{m}^{3}$ during periods I, II, III, and IV, respectively. Mass ratio of $\mathrm{PM}_{2.5} / \mathrm{PM}_{10}$ during the four periods was $82 \%, 81 \%$, $61 \%$, and $55 \%$, respectively. A higher $\mathrm{PM}_{2.5} / \mathrm{PM}_{10}$ ratio in period II was consistent with the enhanced secondary formation during this period. $\mathrm{CO}$ concentrations were $0.952,0.682,0.633$, and $0.625 \mathrm{mg} / \mathrm{m}^{3}$. Notably, $\mathrm{O}_{3}$ exhibited a different variation trend from gaseous pollutants and particulate matters. Concentrations of $\mathrm{O}_{3}$ were $36,64,64$, and $93 \mu \mathrm{g} / \mathrm{m}^{3}$ during the four periods. Compared to period $\mathrm{I}_{3} \mathrm{O}_{3}$ increased by $77.8 \%$ during period II $\left(64 \mu \mathrm{g} / \mathrm{m}^{3}\right)$. Huang et al. (2020) explained that large decreases in $\mathrm{NO}_{x}$ emissions increased $\mathrm{O}_{3}$ and nighttime $\mathrm{NO}_{3}$ radical formation, leading to increased atmospheric oxidizing capacity, which further facilitated the formation of secondary particulate matter.
Spatial-temporal variation

Figure 3 shows the daily variation of $\mathrm{NO}_{2}, \mathrm{PM}_{2.5}$, $\mathrm{PM}_{10}, \mathrm{SO}_{2}, \mathrm{CO}$, and $\mathrm{O}_{3}$ in YRD during the four periods. Hourly $\mathrm{NO}_{2}$ displayed a bimodal distribution during the four periods, with a morning peak and a nighttime peak. $\mathrm{NO}_{2}$ at the nighttime peak $\left(47 \mu \mathrm{g} / \mathrm{m}^{3}\right)$ was higher than that at the morning peak $\left(40 \mu \mathrm{g} / \mathrm{m}^{3}\right)$ before the COVID-19 outbreak (period I), whereas $\mathrm{NO}_{2}$ concentrations at the morning peak and nighttime peak were similar after the COVID-19 outbreak (periods II, III, and IV). $\mathrm{PM}_{2.5}$ and $\mathrm{PM}_{10}$ presented a bimodal distribution during the four periods. Concentrations of $\mathrm{PM}_{2.5}$ and $\mathrm{PM}_{10}$ at the nighttime peak were higher than that at the morning peak during period II. The gap between nighttime $\mathrm{PM}_{2.5}$ concentration during period II and period III was greater than that in the daytime. However, $\mathrm{PM}_{2.5} / \mathrm{PM}_{10}$ ratios in the day (07:00-18:00, 86\%, 86\%, 62\%, and 58\%, respectively) were higher than that at night (19:00-06:00, $81 \%, 76 \%, 57 \%$, and $49 \%$, respectively) during the four periods, indicating stronger secondary formation in daytime. $\mathrm{SO}_{2}$ exhibited a unimodal distribution during the four periods. However, the peak hour
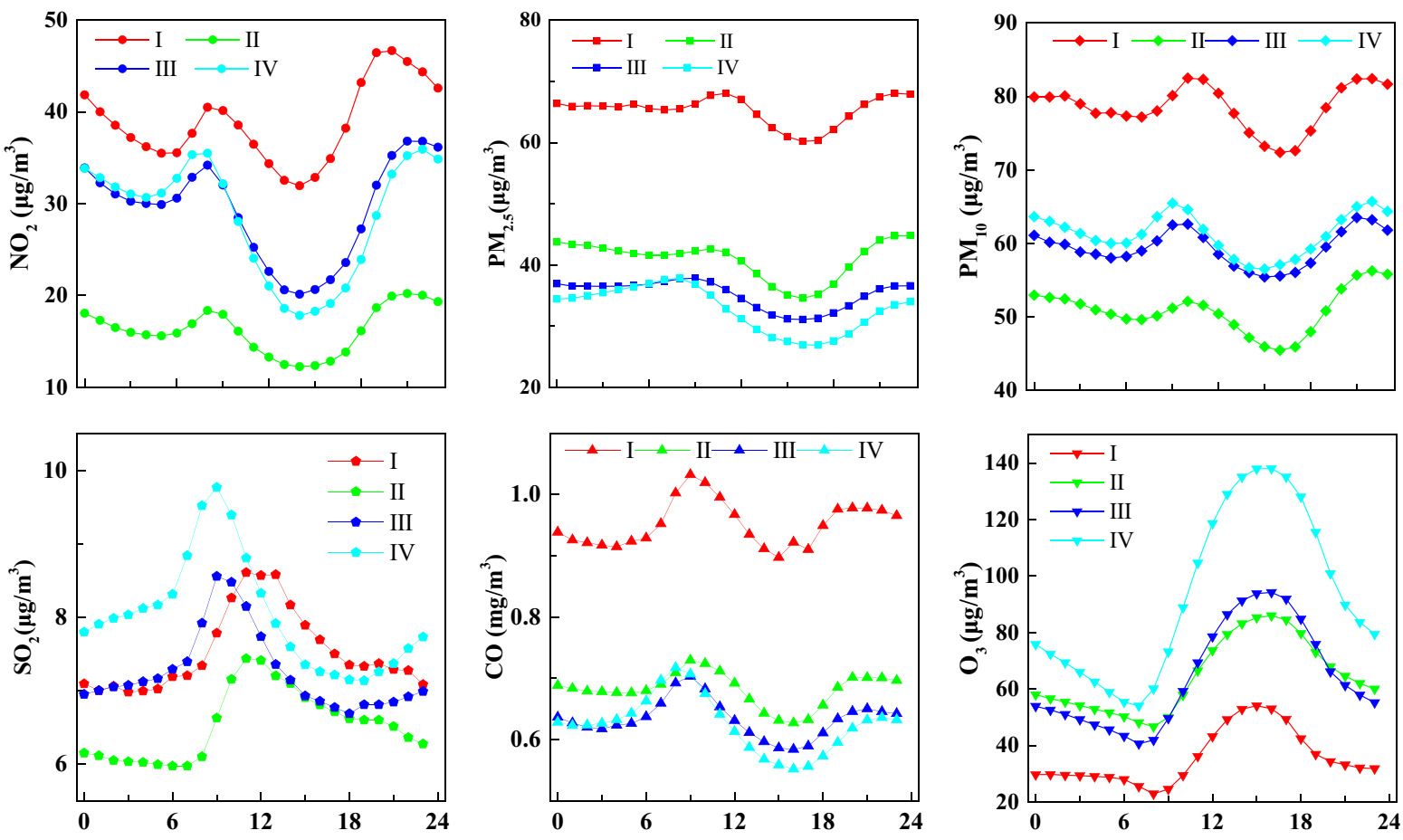

Fig. 3 Daily patterns of $\mathrm{NO}_{2}, \mathrm{PM}_{2.5}, \mathrm{PM}_{10}, \mathrm{SO}_{2}, \mathrm{CO}$, and $\mathrm{O}_{3}$ in the YRD during the four periods 
when $\mathrm{SO}_{2}$ showing the highest concentration differed. Compared to period II, the peak hour of $\mathrm{SO}_{2}$ came earlier during periods III and IV. The results agreed well with the previous study conducted in Wuhan that the lockdown due to the COVID-19 outbreak modified the diurnal variation patterns of $\mathrm{PM}_{2.5}$ sources (Zheng et al., 2020). CO presented a similar daily variation to $\mathrm{PM}_{2.5}$, with relatively higher concentration during period II, compared to periods III and IV. $\mathrm{O}_{3}$ exhibited similar daily variation during the four the periods, with a large peak at 15:00. The average $\mathrm{O}_{3}$ concentrations during periods II and III were similar. However, nighttime $\mathrm{O}_{3}$ during period II was higher than that in period III. A considerable level of nocturnal $\mathrm{O}_{3}$ favors nocturnal $\mathrm{NO}_{3}$ radical formation during period II (Sun et al., 2018).

Spatial variation of $\mathrm{NO}_{2}, \mathrm{PM}_{2.5}, \mathrm{PM}_{10}, \mathrm{SO}_{2}, \mathrm{CO}$, and $\mathrm{O}_{3}$ in YRD during the four periods is depicted in Fig. 4. Nanjing, Hangzhou, and Hefei were provincial capital cities of Anhui, Jiangsu, and Zhejiang, respectively. Higher concentrations of $\mathrm{NO}_{2}$ were observed in central YRD, including Shanghai, the provincial capital cities, and the adjacent cities during the four periods. In period $\mathrm{I}, \mathrm{NO}_{2}$ in central YRD were at the level of $40-60 \mu \mathrm{g} / \mathrm{m}^{3}$. $\mathrm{NO}_{2}$ concentrations in 33 cites (80\%) decreased to less than $20 \mu \mathrm{g} / \mathrm{m}^{3}$ during period II, among which included $\mathrm{NO}_{2}$ in the southernmost three cities in YRD dropping to less than $10 \mu \mathrm{g} / \mathrm{m}^{3}$. After the resumption of work and production, $\mathrm{NO}_{2}$ in the central YRD increased to $30-40 \mu \mathrm{g} / \mathrm{m}^{3}$. However, $\mathrm{PM}_{2.5}$ exhibited a very different spatial distribution with $\mathrm{NO}_{2}$ in the YRD. The highest average $\mathrm{PM}_{2.5}$ concentrations $\left(110-120 \mu \mathrm{g} / \mathrm{m}^{3}\right)$ were observed in the northern YRD, and $\mathrm{PM}_{2.5}$ concentrations in the YRD shows a decreasing trend from north to south during period I. Higher $\mathrm{PM}_{2.5}$ concentration was also measured in the northern part of the YRD during the period II, despite lower $\mathrm{NO}_{2}$ in this area. $\mathrm{PM}_{2.5}$ in northern YRD during period II was higher than that in periods III and IV, whereas $\mathrm{PM}_{2.5}$ concentrations in southern YRD during periods II, III, and IV were similar. The spatial distribution of $\mathrm{PM}_{10}$ in the YRD was similar to $\mathrm{PM}_{2.5}$, with a higher concentration in the northern YRD than that in the southern YRD during the four periods. However, increased $\mathrm{PM}_{10}$ in the southern YRD during periods III and IV was observed when compared to that in period II, which was different from $\mathrm{PM}_{2.5}$. The difference in the spatial and temporal distribution of $\mathrm{PM}_{2.5}$ and $\mathrm{PM}_{10}$ indicated that road dust and construction dust are the main sources of $\mathrm{PM}_{10}$ in urban YRD.

Concentrations of $\mathrm{SO}_{2}$ in the YRD displayed no significant difference in spatial variation during the four periods. $\mathrm{SO}_{2}$ in most cities in the YRD were less than $10 \mu \mathrm{g} / \mathrm{m}^{3}$, with $\mathrm{SO}_{2}$ of a few cities ranging from 10 to $20 \mu \mathrm{g} / \mathrm{m}^{3}$. This $\mathrm{SO}_{2}$ level was still higher when compared to Barcelona, Spain (1.0-2.6 $\left.\mu \mathrm{g} / \mathrm{m}^{3}\right)$, and lower than that in India $\left(10-30 \mu \mathrm{g} / \mathrm{m}^{3}\right)$ during the COVID-19 epidemic (Sharma et al., 2020; Singh \& Chauhan, 2020; Tobias et al., 2020). CO exhibited similar spatial variation to $\mathrm{PM}_{2.5}$ during the periods I and II, with a higher concentration in the northern YRD and lower concentration in the southern YRD.

Unlike $\mathrm{NO}_{2}, \mathrm{O}_{3}$ in the YRD shows no significant difference in spatial distribution during periods I, II, and III. $\mathrm{O}_{3}$ in the northern YRD seems higher than that in the southern YRD during the period IV. According to media reports (https://www.sohu.com/a/ 370746933_440288), Wenzhou, the southernmost city in the YRD, became the second worst-hit area next to Hubei Province, of which the capital city is Wuhan. Thus, $\mathrm{NO}_{2}$ concentration in Wenzhou was very low $\left(7 \mu \mathrm{g} / \mathrm{m}^{3}\right)$ during the period II due to the most rigorous control measures, whereas $\mathrm{O}_{3}$ concentration $\left(70 \mu \mathrm{g} / \mathrm{m}^{3}\right)$ in Wenzhou during the period II was at a higher level (Fig. 4). A similar $\mathrm{O}_{3}$ increase was reported in Milan, Italy, during the lockdown (Collivignarelli et al., 2020). The elevated $\mathrm{O}_{3}$ concentration during the lockdown was probably due to less NO emission and the weakened NO titration effect (Tan et al., 2009).

Period I represents a normal period, and period II represents the most rigorous control period due to the novel coronavirus. Percent changes (a positive value means an increase and a negative value means decrease) of the air pollutants in the YRD during period II when compared to the period I are mapped in Fig. 5. $\mathrm{NO}_{2}$ in the most YRD cities decreased by more than 50\% (average 58.2\%) during the period II and $\mathrm{NO}_{2}$ in the southern YRD even reduced up to $70-80 \%$. $\mathrm{PM}_{2.5}$ and $\mathrm{PM}_{10}$ in the most YRD cities decreased by $30-40 \%$ during period II, with the average proportion of $37 \%$ and $35 \%$, respectively. Averagely, the proportion of $\mathrm{O}_{3}$ increase in the YRD was $81 \%$ during period II and that was $101-155 \%$ in the provincial capital cities. 
Fig. 4 Spatial variation of $\mathrm{NO}_{2}, \mathrm{PM}_{2.5}, \mathrm{PM}_{10}, \mathrm{SO}_{2}$, $\mathrm{CO}$, and $\mathrm{O}_{3}$ in the YRD during the four periods. The provincial capital cities and Shanghai were labeled
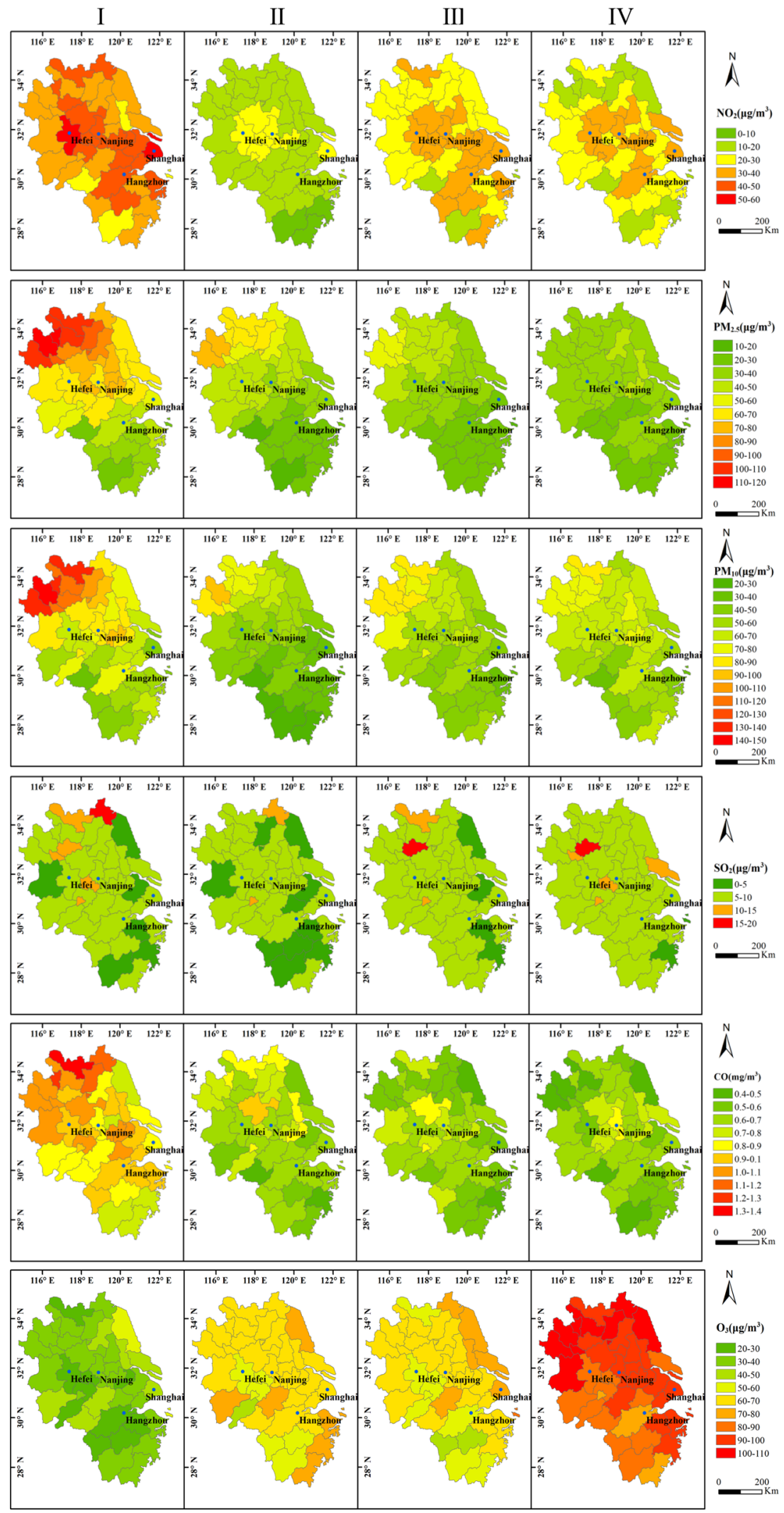

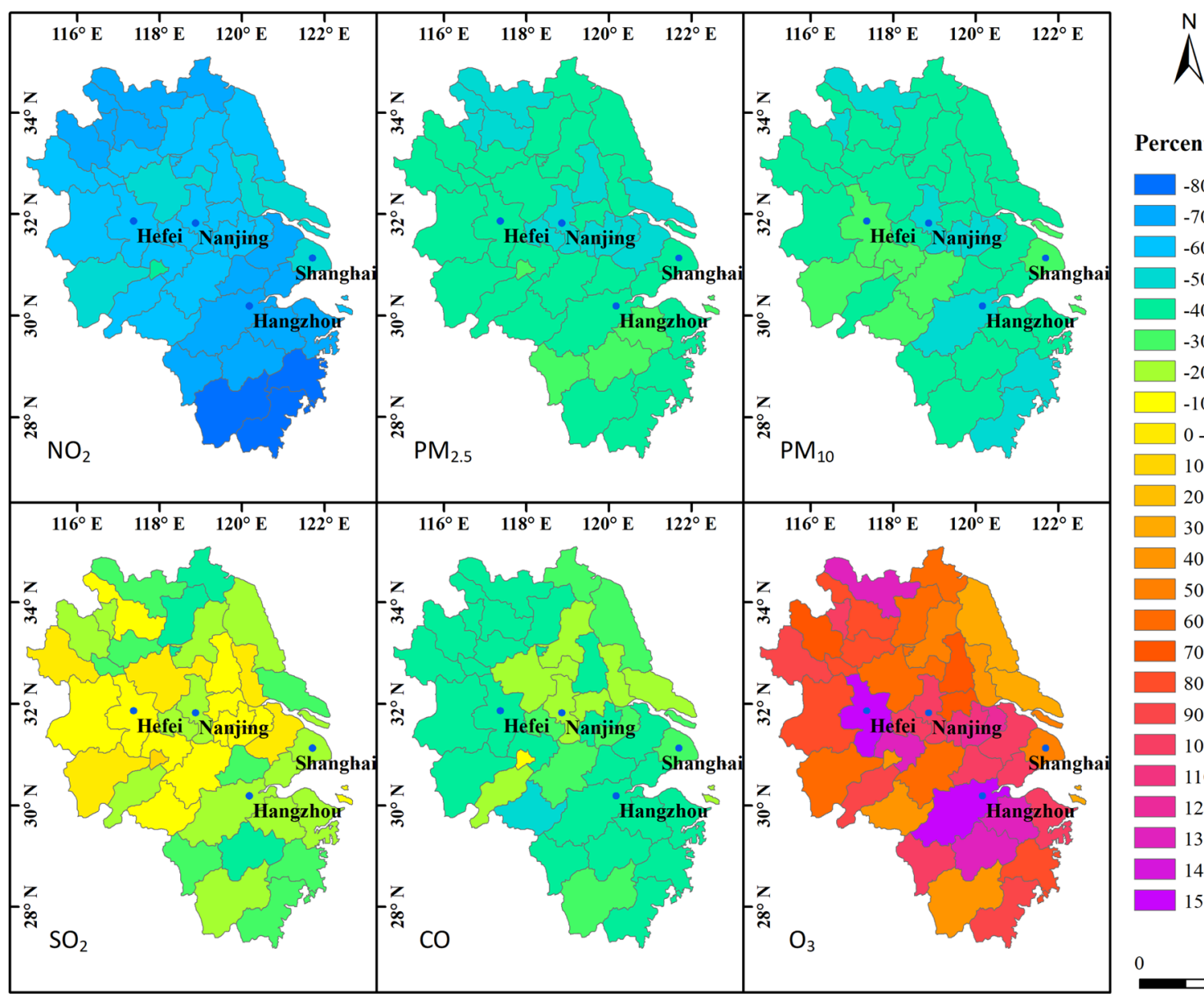

Percent(\%)

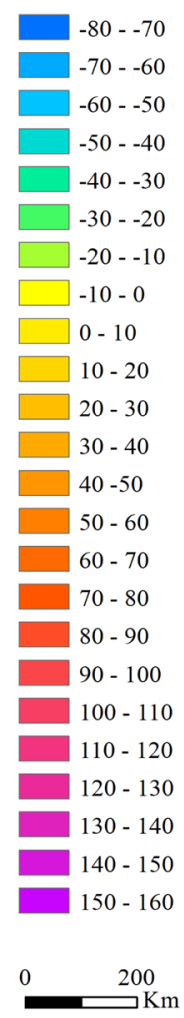

Fig. 5 Percent changes of the air pollutants in the YRD during period II when compared to the period I. A negative value indicates decrease and a positive value indicates an increase

\section{Analysis of meteorological conditions}

Time series of daily average of precipitation, total column water vapor, and wind speed in the YRD region during the study period in 2020 are in Fig. S1. It seems that precipitation was evenly distributed and wind speed was similar during the study period in 2020. Total column water vapor shows an increasing trend from January to May, 2020. Independent-sample $T$ test was applied to exam the significant difference of meteorological parameters during the four periods. There was no significant difference $(P \gg 0.05)$ in precipitation between the four periods, as well as wind speed. Significant differences were obtained for the total column water vapor in the four periods, verifying an increasing trend of total column water vapor. The speed and direction of the horizontal wind at a height of $10 \mathrm{~m}$ above the ground surface in the YRD region during the four periods in 2020 are depicted in Fig. 6. Wind fields during period I and period II were similar, with the prevailing wind from the north and northeast. Compared to period I and period II, the predominant wind direction changed in period III and period IV, with the prevailing wind from the east, southeast, and south.

\section{Comparison with 2019}

For comparison, average concentrations of pollutants in the four periods in 2020 with that in 2019 are listed in Table 1. Time series of hourly concentrations of 

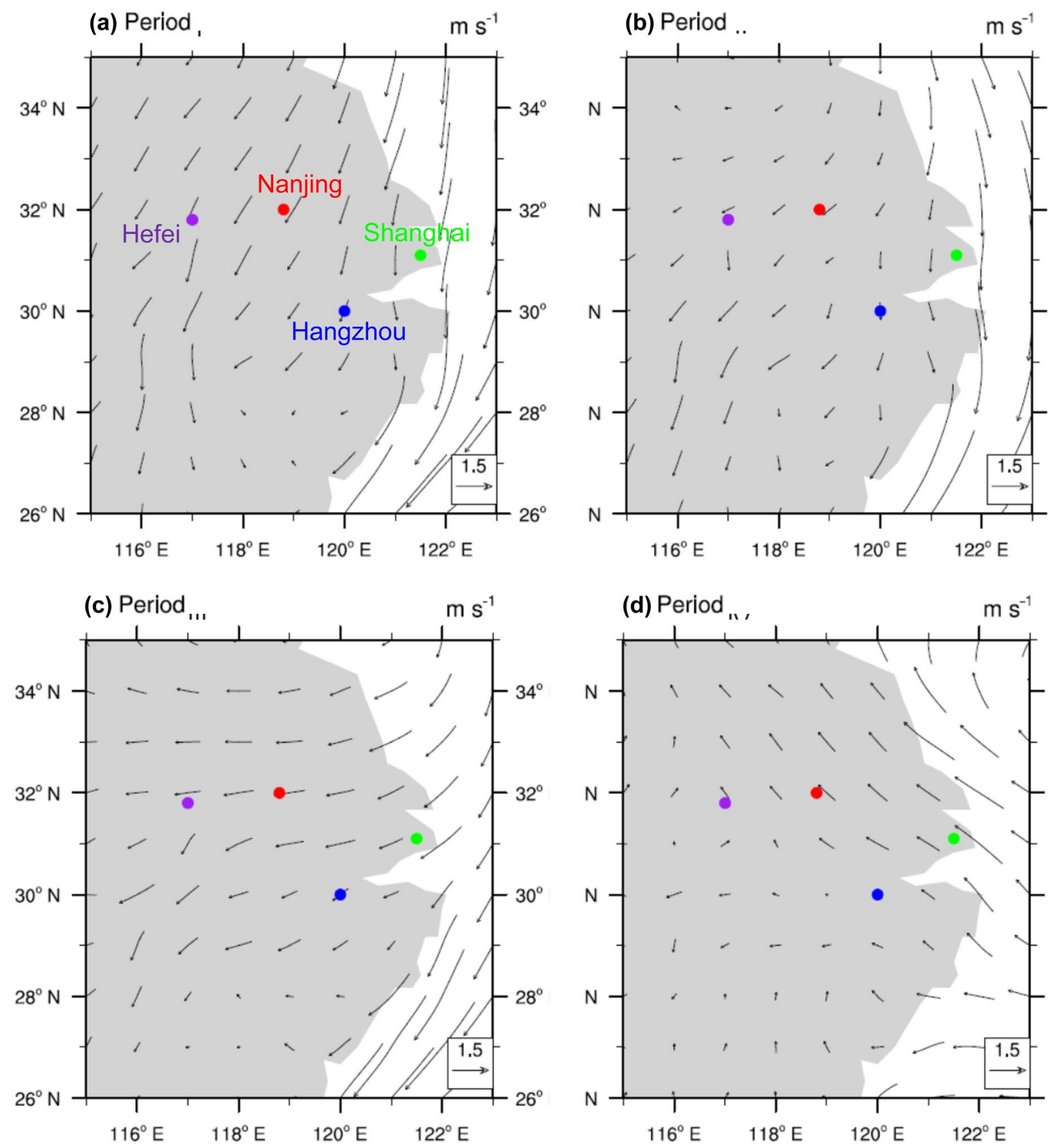

Fig. 6 The speed and direction of the horizontal wind at a height of $10 \mathrm{~m}$ above the ground surface in the YRD region during the four periods in 2020

pollutants during the four periods in 2020 and 2019 are depicted in Fig. S2. From Table 1, concentrations of pollutants, except $\mathrm{O}_{3}$, generally decreased during the four periods in 2020 when compared to 2019. However, a larger reduction of pollutants was observed during period II, which was closely related to the strict lockdown policy in period II. For example, $\mathrm{NO}_{2}$ during the numbered four periods in 2020 decreased by $18.2 \%, 45.1 \%, 24.8 \%$, and $3.9 \%$, respectively, when compared to that in 2019. Similarly, 
Table 1 Comparison of average concentrations of pollutants during the four periods in 2020 and 2019

*Percent changes of the air pollutants in the YRD during the four periods in 2020 when compared to 2019. A negative value indicates decrease and a positive value indicates an increase

\begin{tabular}{|c|c|c|c|c|c|}
\hline Pollutants & Year & Period I & Period II & Period III & Period IV \\
\hline \multirow[t]{3}{*}{$\mathrm{PM}_{2.5}\left(\mu \mathrm{g} / \mathrm{m}^{3}\right)$} & 2020 & 65 & 41 & 35 & 33 \\
\hline & 2019 & 74 & 59 & 53 & 34 \\
\hline & Percent change $(\%)^{*}$ & -12.3 & -30.2 & -33.2 & -3.6 \\
\hline \multirow[t]{3}{*}{$\mathrm{PM}_{10}\left(\mu \mathrm{g} / \mathrm{m}^{3}\right)$} & 2020 & 79 & 51 & 59 & 61 \\
\hline & 2019 & 102 & 78 & 84 & 63 \\
\hline & Percent change $(\%)$ & -22.9 & -35.1 & -29.0 & -2.8 \\
\hline \multirow[t]{3}{*}{$\mathrm{NO}_{2}\left(\mu \mathrm{g} / \mathrm{m}^{3}\right)$} & 2020 & 39 & 16 & 29 & 29 \\
\hline & 2019 & 47 & 30 & 39 & 30 \\
\hline & Percent change $(\%)$ & -18.2 & -45.1 & -24.8 & -3.9 \\
\hline \multirow[t]{3}{*}{$\mathrm{SO}_{2}\left(\mu \mathrm{g} / \mathrm{m}^{3}\right)$} & 2020 & 8 & 7 & 7 & 8 \\
\hline & 2019 & 11 & 8 & 10 & 9 \\
\hline & Percent change (\%) & -28.7 & -17.7 & -28.4 & -9.5 \\
\hline \multirow[t]{3}{*}{$\mathrm{O}_{3}\left(\mu \mathrm{g} / \mathrm{m}^{3}\right)$} & 2020 & 36 & 64 & 64 & 93 \\
\hline & 2019 & 30 & 49 & 67 & 83 \\
\hline & Percent change $(\%)$ & 20.3 & 32.3 & -3.8 & 12.5 \\
\hline \multirow[t]{3}{*}{$\mathrm{CO}\left(\mathrm{mg} / \mathrm{m}^{3}\right)$} & 2020 & 0.952 & 0.682 & 0.633 & 0.625 \\
\hline & 2019 & 1.033 & 0.850 & 0.754 & 0.638 \\
\hline & Percent change $(\%)$ & -7.8 & -19.8 & -16.0 & -2.1 \\
\hline
\end{tabular}

$\mathrm{PM}_{10}$ during the four periods in 2020 decreased by $22.9 \%, 35.1 \%, 29 \%$, and $2.8 \%$, respectively. In contrast to other pollutants, $\mathrm{O}_{3}$, a typical secondary pollutant formed from photochemical reaction, presented an increasing trend during the study period in 2020 , compared to 2019. Further, a larger increase in $\mathrm{O}_{3}$ was observed in period II in 2020 (32.3\%), which provided evidence that $\mathrm{O}_{3}$ increased due to reduction of $\mathrm{NO}_{x}$ emission during period II. $\mathrm{SO}_{2}$ in period II in 2020 was similar to that in 2019. In period IV, concentrations of pollutants in 2020 , except $\mathrm{O}_{3}$, were similar to that in 2019 , which was directly associated with the intensive resumption of work and production on national scale.

Figure 7 shows percentage changes in the concentrations of pollutants, electricity consumption, and highway transportation in YRD in 2020 when compared to the corresponding monthly average in 2019 . The monthly average concentrations of air pollutants in YRD were downloaded from Yangtze River Delta regional air quality forecast business platform. Compared to 2019, the six pollutants indicating air quality in the YRD decreased in 2020 except $\mathrm{O}_{3}$. For temporal comparison, a larger reduction of pollutants in the YRD was observed in the first three months of 2020, especially in February. For example, $\mathrm{NO}_{2}, \mathrm{PM}_{2.5}$, $\mathrm{PM}_{10}, \mathrm{SO}_{2}$, and $\mathrm{CO}$ decreased by $37 \%, 38 \%, 34 \%$,
19\%, and 26\% in February, 2020, respectively. Similar results were reported in Wuhan in central China, which was attributed to emission reduction $(92.0 \%)$ rather than meteorological conditions during the lockdown (Zheng et al., 2020). $\mathrm{O}_{3}$ (8-h maximum) in the YRD presented an increasing trend in 2020 when compared to 2019. $\mathrm{O}_{3}$ (8-h maximum) increased by $14 \%, 17 \%$, and $18 \%$ in January, February, and April, respectively.

Seventy-three percent of the total freight transport in China was achieved by highway transportation in 2019. Compared to 2019, reduction (1.4-35.2\%) of highway freight transportation in the YRD was recorded from January to May in 2020, particularly in February (Fig. 7b). For example, highway freight transportation in Shanghai, Jiangsu, Zhejiang, and Anhui decreased by $27.2 \%, 35.2 \%, 21.4 \%$, and $19.2 \%$ in February 2020, respectively, and started to resume since March. Compared to highway freight transportation, a larger reduction of highway passenger transportation was recorded in 2020 than that in 2019. No significant resumption of highway passenger transportation was observed in the YRD from March in 2020. For example, highway passenger transportation reduced by 50.6-60.3\% in February, and that was $37.9-70.8 \%$ in May 2020, compared to the same period in 2019. 
(a)

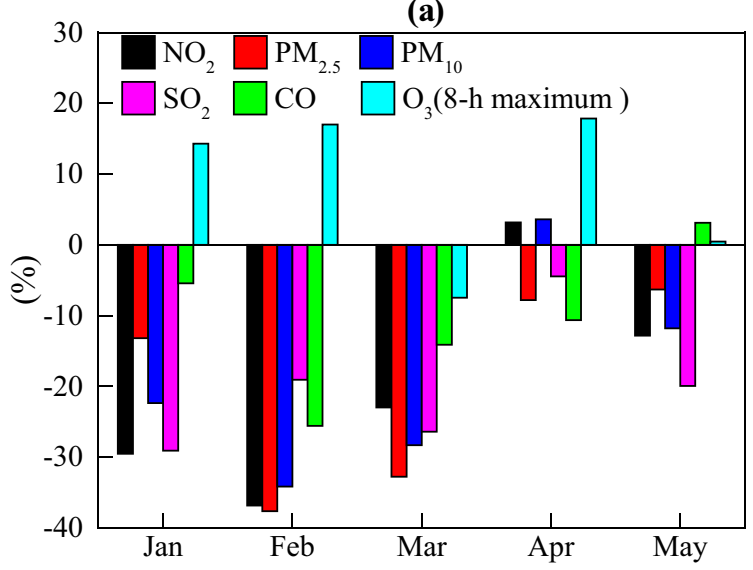

(b)

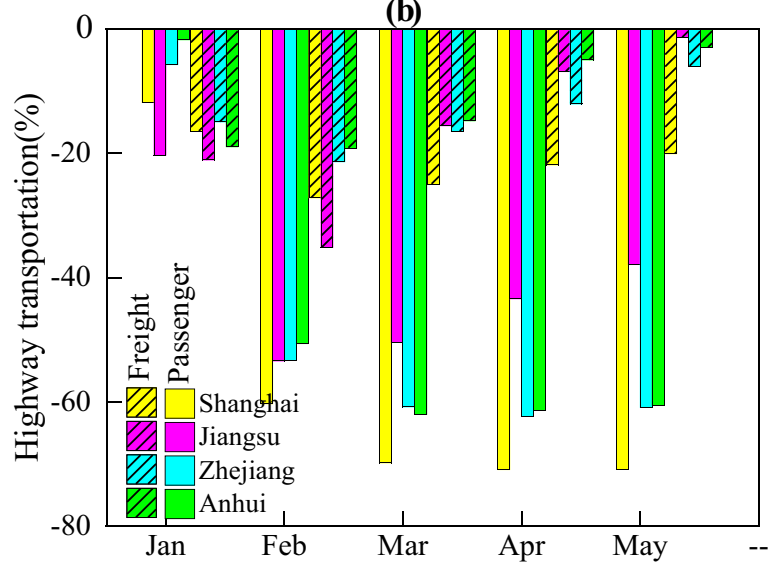

(c)

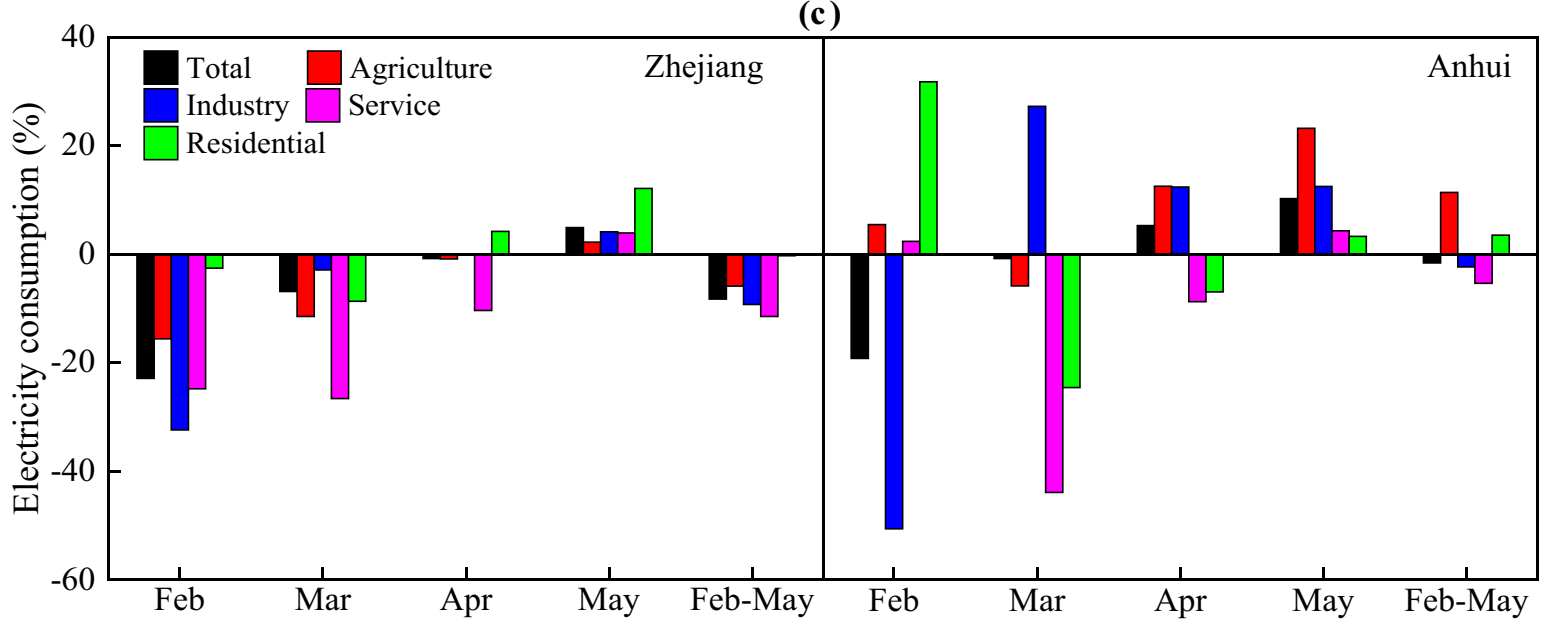

Fig. 7 Percentage changes in a the concentrations of pollutants, b highway transportation, and c electricity consumption in the YRD in 2020 when compared to the corresponding monthly average in 2019 . The monthly electricity consumption

Total electricity consumption is closely related to industrial production because electricity consumption from industry accounts for a dominant proportion. The electricity consumption from industry accounted for $69 \%$ of the total electricity consumption in China, with service, residential, and agriculture proportion of $16 \%, 14 \%$, and $1 \%$, respectively (National Energy Administration, 2020). From Fig. 7c, compared to 2019, the total electricity consumption of Zhejiang and Anhui reduced in February in 2020, which was resulted from large reduction of electricity consumption from industry. For example, industrial electricity consumption of Zhejiang and Anhui reduced by $32.4 \%$ and $50.6 \%$, respectively, which was related to the structure in Jiangsu and Shanghai during the study period was not available. Source: (Ministry of Transport of the People's Republic of China, 2020; Statistics Bureau of Anhui Province, 2020; Statistics Bureau of Zhejiang Province, 2020)

lockdown policy. The total electricity consumption in the YRD during the study period in 2020 slightly reduced when compared to that in 2019.

In summary, the air quality in the YRD region greatly improved during the study period in 2020 due to the countermeasures to interrupt the transmission of COVID-19 when compared with the same period in 2019. However, increasing $\mathrm{O}_{3}$ is worthy of attention.

\section{Conclusion}

This lockdown in China due to the novel coronavirus outbreak provided a unique chance to test the 
sensitivity of primary emission reduction on air quality. Our results show that $\mathrm{NO}_{2}$ significantly decreased and $\mathrm{SO}_{2}$ almost remain unchanged in the YRD region during the period of the COVID-19 outbreak when the most rigorous control measures were implemented. Under the circumstances, $\mathrm{PM}_{2.5}$ in the northern YRD areas still exhibited higher concentrations when compared to the case in which $\mathrm{NO}_{2}$ increased, implying enhanced secondary formation. The results demonstrated that $\mathrm{PM}_{2.5}$ shows a nonlinear response to the reduction of its precursors and this phenomenon varies from region to region. $\mathrm{O}_{3}$ increase was also recorded during the COVID-19 outbreak, which was probably related to the weakened NO titration effect. Further researches need to probe into the nonlinear response mechanism and regulation principle of $\mathrm{PM}_{2.5}, \mathrm{O}_{3}$, and their precursors.

Acknowledgements Great appreciation to Dr. Yafei Yan for her effort in meteorological analysis.

Author contribution Lan Yao: conceptualization, data curation, writing - original draft, supervision, funding acquisition, and project administration. Weiyue Li: data curation, writingreview \& editing, and funding acquisition. Yi Du: data curation and formal analysis. All authors read and approved the final manuscript.

Funding This work was supported by General Research Fund of Shanghai Normal University (No. SK202012), the Natural Science Foundation of Shanghai (No. 19ZR1437500), and National Natural Science Foundation of China (No. 42005089).

Data Availability The datasets analyzed during the current study are available from the corresponding author on reasonable request.

\section{Declarations}

Competing interests The authors declare no competing interests.

\section{References}

Chang, Y., Huang, R. J., Ge, X, Huang, X., Hu, J., Duan, Y., Zou, Z., Liu, X., Lehmann, M. F. (2020). Puzzling haze events in China during the coronavirus (COVID19) shutdown. Geophysical Research Letters, 47, e2020GL088533. https://doi.org/10.1029/2020GL088533

Collivignarelli, M. C., Abba, A., Bertanza, G., Pedrazzani, R., Ricciardi, P., \& Miino, M. C. (2020). Lockdown for CoViD-2019 in Milan: what are the effects on air quality? Science of the Total Environment, 732. https:// doi.org/10.1016/j.scitotenv.2020.139280

Graham, R. M., Hudson, S. R., \& Maturilli, M. (2019). Improved performance of ERA5 in Arctic gateway relative to four global atmospheric reanalyses[J]. Geophysical Research Letters, 46(11), 6138-6147. https://doi. org/10.1029/2019GL082781

Guo, J., He, J., Liu, H., Miao, Y., Liu, H., \& Zhai, P. (2016). Impact of various emission control schemes on air quality using WRF-Chem during APEC China 2014. Atmospheric Environment, 140, 311-319. https://doi.org/10. 1016/j.atmosenv.2016.05.046

Health Commission of Zhejiang Province. (2020). Daily report on COVID-19. http://www.zjwjw.gov.cn/col/ col1202101/index.html (accessed on 29 July 2020).

Huang, K., Zhuang, G., Lin, Y., Wang, Q., Fu, J. S., Zhang, R., Li, J., Deng, C., \& Fu, Q. (2012). Impact of anthropogenic emission on air quality over a megacityrevealed from an intensive atmospheric campaign during the Chinese Spring Festival. Atmospheric Chemistry and Physics, 12, 11631-11645. https://doi.org/10.5194/ acp-12-11631-2012

Huang, X., Ding, A., Gao, J., Zheng, B., Zhou, D., Qi, X., Tang, R., Ren, C., Nie, W., Chi, X., Wang, J., Xu, Z., Chen, L., Li, Y., Che, F., Pang, N., Wang, H., Tong, D., Qin, W., \& He, H. (2020). Enhanced secondary pollution offset reduction of primary emissions during COVID-19 lockdown in China. National Science Review, nwaa137. https://doi.org/10.1093/nsr/nwaa137

Jiang, Q., Sun, Y. L., Wang, Z., \& Yin, Y. (2015). Aerosol composition and sources during the Chinese Spring Festival: Fireworks, secondary aerosol, and holiday effects. Atmospheric Chemistry and Physics, 15, 6023-6034. https://doi.org/10.5194/acp-15-6023-2015

Jiangsu Commission of Health. (2020). Daily report on COVID-19. http://www.jshealth.com/xxgk/yqdt/index.html (accessed on 29 July 2020).

Liu, H., Wang, X. M., Zhang, J. P., He, K. B., Wu, Y., \& Xu, J. Y. (2013). Emission controls and changes in air quality in Guangzhou during the Asian Games. Atmospheric Environment, 76, 81-93. https://doi.org/10.1016/j.atmosenv. 2012.08.004

Liu, Y., Ning, Z., Chen, Y., Guo, M., Liu, Y., Gali, N. K., Sun, L., Duan, Y., Cai, J., Westerdahl, D., Liu, X., Xu, K., Ho, K. F., Kan, H., Fu, Q., \& Lan, K. (2020). Aerodynamic analysis of SARS-CoV-2 in two Wuhan hospitals. Nature, 582, 557-560. https://doi.org/10.1038/s41586-020-2271-3

Ministry of Transport of the People's Republic of China. (2020). Monthly report on highway transportation volume of freight and passenger. http://www.mot.gov.cn/tongjishuju/ gonglu/ (accessed on 29 July 2020).

National Energy Administration. (2020). National electric power industry statistics in 2019. http://www.nea.gov.cn/ 2020-01/20/c_138720881.htm (accessed on 29 July 2020)

National Health Commission of the People's Republic of China. (2020). Daily report on COVID-19. http://www.nhc.gov. cn/xcs/yqtb/list_gzbd.shtml (accessed on 29 July 2020).

National Health Commission of the People's Republic of China. (2019). Report of China's migrant population development 2018. China Population Press. 
Shanghai Municipal Health Commission. (2020). Daily report on COVID-19. http://wsjkw.sh.gov.cn/yqtb/index. html (accessed on 29 July 2020)

Sharma, S., Zhang, M. Y, Anshika Gao, J. S., Zhang, H. L., \& Kota, S. H. (2020). Effect of restricted emissions during COVID-19 on air quality in India. Science of the Total Environment, 728. https://doi.org/10.1016/j.scitotenv.2020. 138878

Singh, R. P., \& Chauhan, A. (2020). Impact of lockdown on air quality in India during COVID-19 pandemic. Air Quality, Atmosphere and Health, 13, 921-928. https://doi.org/10. 1007/s11869-020-00863-1

Statistics Bureau of Anhui Province. (2020). Monthly data on Energy. http://data.ahtjj.gov.cn/ydsj/index.jhtml (accessed on 29 July 2020).

Statistics Bureau of Zhejiang Province. (2020). Monthly data on Energy. http://data.tjj.zj.gov.cn/page/zbcx/yksjDetail.jsp? $\mathrm{ztCode}=12 \& \mathrm{bgq}=20200006 \& \mathrm{dqCode}=33 \&$ orgCode $=$ $33 \& \mathrm{ztName}=\% 25 \mathrm{E} 8 \% 2583 \% 25 \mathrm{BD} \% 25 \mathrm{E} 6 \% 25 \mathrm{BA} \%$ 2590 (accessed on 29 July 2020).

Sun, P., Nie, W., Chi, X., Xie, Y., Huang, X., Xu, Z., Qi, X., Xu, Z., Wang, L., Wang, T., Zhang, Q., \& Ding, A. (2018). Two years of online measurement of fine particulate nitrate in the western Yangtze River Delta: Influences of thermodynamics and $\mathrm{N}_{2} \mathrm{O}_{5}$ hydrolysis. Atmospheric Chemistry and Physics, 18, 17177-17190. https://doi.org/ 10.5194/acp-18-17177-2018

Tan, P. H., Chou, C., Liang, J. Y., Chou, C. C. K., \& Shiu, C. J. (2009). Air pollution "holiday effect" resulting from the Chinese New Year. Atmospheric Environment, 43, 21142124. https://doi.org/10.1016/j.atmosenv.2009.01.037

Tang, G., Zhu, X., Hu, B., Xin, J., Wang, L., Munkel, C., Mao, G., \& Wang, Y. (2015). Impact of emission controls on air quality in Beijing during APEC 2014: Lidar ceilometer observations. Atmospheric Chemistry and Physics, 15, 12667-12680. https://doi.org/10.5194/acp-15-12667-2015

Tao, J., Zhang, L., Zhang, Z., Huang, R., Wu, Y., Zhang, R., Cao, J., \& Zhang, Y. (2015). Control of $\mathrm{PM}_{2.5}$ in Guangzhou during the 16th Asian Games period: Implication for hazy weather prevention. Science of the Total Environment, 508, 57-66. https://doi.org/10.1016/j.scitotenv. 2014.11.074

Tobias, A., Carnerero, C., Reche, C., Massague, J., Via, M., Minguillon, M.C., Alastuey, A., \& Querol, X. (2020). Changes in air quality during the lockdown in Barcelona (Spain) one month into the SARS-CoV-2 epidemic. Science of the Total Environment, 726. https://doi.org/10. 1016/j.scitotenv.2020.138540

Wang, P., Chen, K., Zhu, S., Wang, P., \& Zhang, H. (2020). Severe air pollution events not avoided by reduced anthropogenic activities during COVID-19 outbreak. Resour Conserv Recy, 158, 104814. https://doi.org/10.1016/j. resconrec.2020.104814
Wang, T., Nie, W., Gao, J., Xue, L., Gao, X. M., Wang, X., Qiu, J., Poon, C. N., Meinardi, S., \& Blake, D. R. (2010). Air quality during the 2008 Beijing Olympics: Secondary pollutants and regional impact. Atmospheric Chemistry and Physics, 10, 7603-7615. https://doi.org/10.5194/ acp-10-7603-2010

Witte, J. C., Schoeberl, M. R., Douglass, A. R., Gleason, J. F., Krotkov, N. A., Gille, J. C., Pickering, K. E., \& Livesey, N. J. (2009). Satellite observations of changes in air quality during the 2008 Beijing Olympics and Paralympics. Geophysical Research Letters, 36. https://doi.org/10.1029/ 2009GL039236

World Health Organization. (2020). Coronavirus disease (COVID-19) pandemic. Available online: https://www.who. int/emergencies/diseases/novel-coronavirus-2019 (accessed on 29 July 2020).

Xu, W., Liu, X., Liu, L., Dore, A. J., Tang, A., Lu, L., Wu, Q., Zhang, Y., Hao, T., \& Pan, Y. (2019). Impact of emission controls on air quality in Beijing during APEC 2014: Implications from water-soluble ions and carbonaceous aerosol in $\mathrm{PM}_{2.5}$ and their precursors. Atmospheric Environment, 210, 241-252. https://doi.org/10.1016/j.atmosenv.2019.04. 050

Yao, L., Wang, D., Fu, Q., Qiao, L., Wang, H., Li, L., Sun, W., Li, Q., Wang, L., Yang, X., Zhao, Z., Kan, H., Xian, A., Wang, G., Xiao, H., \& Chen, J. (2019). The effects of firework regulation on air quality and public health during the Chinese Spring Festival from 2013 to 2017 in a Chinese megacity. Environment International, 126, 96-106. https://doi.org/10.1016/j.envint.2019.01.037

Yao, Z. L., Zhang, Y. Z., Shen, X. B., Wang, X. T., Wu, Y., \& He, K. B. (2013). Impacts of temporary traffic control measures on vehicular emissions during the Asian Games in Guangzhou, China. J Air Waste Manage, 63, 11-19. https://doi.org/10.1080/10962247.2012.724041

Zhang, R. X., Zhang, Y. Z., Lin, H. P., Feng, X., Fu, T. M., \& Wang, Y. H. (2020). NOx emission reduction and recovery during COVID-19 in East China. Atmosphere, 11, 15. https://doi.org/10.3390/atmos11040433

Zheng, H., Kong, S., Chen, N., Yan, Y., Liu, D., Zhu, B., Xu, K., Cao, W., Ding, Q., Lan, B., Zhang, Z., Zheng, M., Fan, Z., Cheng, Y., Zheng, S., Yao, L., Bai, Y., Zhao, T., \& Qi, S. (2020). Significant changes in the chemical compositions and sources of $\mathrm{PM}_{2.5}$ in Wuhan since the city lockdown as COVID-19. Science of the Total Environment, 739, 140000. https://doi.org/10.1016/j.scitotenv.2020.140000

Publisher's Note Springer Nature remains neutral with regard to jurisdictional claims in published maps and institutional affiliations. 